\title{
Unique insight into microenvironmental changes in colorectal cancer: Ex vivo assessment of matrix metalloprotease-mediated molecular changes in human colorectal tumor tissue and corresponding non-neoplastic adjacent tissue
}

\author{
NICHOLAS WILLUMSEN ${ }^{1,2}$, CECILIE L. BAGER ${ }^{1}$, ANNE-CHRISTINE BAY-JENSEN ${ }^{1}$, STEPHANIE N. KEHLET ${ }^{1}$, \\ HENRIK HARLING ${ }^{3}$, DIANA J. LEEMING ${ }^{1}$, MORTEN A. KARSDAL $^{1}$ and LARS N. JORGENSEN ${ }^{3}$ \\ ${ }^{1}$ Biomarkers and Research, Nordic Bioscience A/S, DK-2730 Herlev; \\ ${ }^{2}$ Department of Endocrinology, University of Southern Denmark, DK-5230 Odense Midt; \\ ${ }^{3}$ Digestive Disease Center, Bispebjerg Hospital, University of Copenhagen, DK-2400 Copenhagen, Denmark
}

Received July 7, 2016; Accepted January 10, 2017

DOI: $10.3892 / \mathrm{ol} .2017 .5900$

\begin{abstract}
Matrix metalloprotease (MMP)-mediated tissue remodeling is one of the malignant changes driving colorectal cancer. Measurement of altered MMP expression/activity is not sufficient to fully understand the effect of MMP-mediated tissue remodeling. Biomarkers are required that specifically reflect the dynamic processes of the MMP-mediated degradation of signature proteins from colorectal tissue. The aim of the present study was to profile and characterize the release of MMP-degraded type III collagen (C3M) and citrullinated and MMP-degraded vimentin (VICM) from tumor tissue and corresponding non-neoplastic adjacent tissue (NAT) in a human colorectal cancer ex vivo model. Colorectal tumor tissue and NAT biopsies from tissue removed during resection of colorectal cancer patients $(n=13)$ were cut into pieces of $2 \mathrm{~mm}^{2}$ and cultured for $24 \mathrm{~h}$ in growth medium. C3M and VICM were evaluated by ELISA. As part of the characterization, C3M was determined subsequent to the tumor tissue being cleaved with recombinant MMP-2/-9 and trypsin. C3M was generated by MMP-2/-9, but not by trypsin. In addition, the level of C3M was significantly elevated in the conditioned medium from tumor tissues $(3.7 \mathrm{ng} / \mathrm{ml})$ compared with that observed in the conditioned medium from the NATs $(2.2 \mathrm{ng} / \mathrm{ml})$ and in the
\end{abstract}

Correspondence to: Mr. Nicholas Willumsen, Biomarkers and Research, Nordic Bioscience A/S, Herlev Hovedgade 207, DK-2730 Herlev, Denmark

E-mail: nwi@nordicbioscience.com

Abbreviations: MMP, matrix metalloprotease; NAT, non-neoplastic adjacent tissue; ECM, extracellular matrix; C3M, MMP-degraded type III collagen; VICM, citrullinated and MMP-degraded vimentin

Key words: colorectal cancer, biomarker, ex vivo, ECM, MMP, protein fingerprint growth medium alone $(1.9 \mathrm{ng} / \mathrm{ml})$. The level of VICM was significantly elevated in the tumor tissues $(0.51 \mathrm{ng} / \mathrm{ml})$ and NATs $(0.52 \mathrm{ng} / \mathrm{ml})$ compared with that in the growth medium alone $(0.03 \mathrm{ng} / \mathrm{ml})$. No differences were detected between the tumor tissues and NATs. No correlation was observed between biomarker levels from the tumor tissue and corresponding NAT, and the biomarker levels did not correlate with tumor stage. In conclusion, the present study provided support of the concept that $\mathrm{C} 3 \mathrm{M}$ and VICM are applicable as tools to investigate dynamic tissue changes of colorectal tumor tissue and corresponding NAT. By the assessment of these specific MMP-mediated molecular changes, the present study provides novel and relevant insight into the dynamic changes of colorectal tumor tissue and corresponding NAT.

\section{Introduction}

Colorectal cancer is not only an accumulation of malignant cells but may be interpreted as an abnormal tissue composed of cancer cells and their stroma, the tumor microenvironment, which is composed of various cell types such as fibroblast, endothelial cells and different cells of the immune system (1). These cells are embedded in, or interact with, the extracellular matrix (ECM). The ECM contains proteins such as collagens, proteoglycans and glycoproteins, and forms a three-dimensional protein structure supporting the cells and tissue (2). In addition to the ECM, multiple proteins such as secreted intracellular proteins, various growth factors and different types of enzymes are also part of the tumor microenvironment (1-3).

During cancer progression, the tumor microenvironment is heavily remodeled due to altered proteolytic activity (3). Matrix metalloproteases (MMPs) are the main proteases responsible for the degradation of extracellular proteins and these are typically upregulated in cancer (4). Limited knowledge is currently available on MMP-mediated degradation of specific proteins of the microenvironment associated with the tumor tissue compared with that in the corresponding non-neoplastic adjacent tissue (NAT) in the same patient. 
In a recent study of the ECM protein composition in normal and malignant colorectal tissue, a total of 37 tumor-specific proteins were identified, including several MMPs (5). However, measurements of altered MMP expression/activity are not sufficient to fully understand the effect of distinct MMP profiles between normal and malignant colorectal tissue. Biomarkers that are capable of reflecting altered MMP expression/activity and, specifically, the dynamic processes of MMP-mediated degradation of signature proteins from the colorectal tissue are required.

A biomarker specifically reflecting MMP-degraded type III collagen (C3M) was previously developed by our group (6). In normal and malignant colorectal tissue, type III collagen is one of the major components of the interstitial ECM compartment (7). The interstitial ECM is an essential component of the fibrotic-like microenvironment identified in numerous solid tumors, and is degraded as part of the inflammation and ECM remodeling associated with tumor progression (8).

Another notable biomarker in this context is citrullinated and MMP-degraded vimentin (VICM). VICM reflects MMP-mediated degradation and citrullination of vimentin (9). Vimentin is an intermediate filament protein shown to be associated with the pathology of inflammatory bowel disease, a group of idiopathic gastrointestinal chronic inflammatory conditions (10), and is expressed in tissue from patients with colorectal cancer (11). Vimentin has been identified on the surface of tumor cells (12) and is released from activated macrophages (10), making it a target for proteolysis and citrullination, a post-translational modification associated with chronic inflammation (13).

Levels of C3M and VICM have been revealed to be elevated in serum from patients with inflammatory bowel disease (14). Levels of C3M have also been revealed to be increased in serum from patients with pancreatic (15), breast and ovarian cancer (16), and levels of VICM have been revealed to be elevated in lung cancer (17).

The present study hypothesized that C3M and VICM may be used as tools to investigate specific MMP-mediated micro-environmental changes in association with colorectal cancer, and hereby increase the knowledge of MMP-mediated degradation of extracellular proteins in tumor tissue compared with that in the NAT of the same patient. The aim of the present study was to provide support for the concept that $\mathrm{C} 3 \mathrm{M}$ and VICM are applicable as tools for the investigation into dynamic tissue changes in an ex vivo culture setting of colorectal tumor tissue and corresponding NAT.

\section{Materials and methods}

Patients/study population. Biopsies from colorectal tumor tissue and NAT from tissue removed during bowel resection in patients with colorectal cancer were obtained subsequent to informed consent and approval by the Ethical Committee of the Capital Region of Denmark (Copenhagen, Denmark; approval no. H-1-2014-048) in compliance with the Helsinki Declaration. Biopsy samples were collected by medical staff immediately after surgery, and stored in Dulbecco's modified Eagle's medium (DMEM) supplemented with Ham's F12 medium (DMEM:F12; VWR International, Søborg, Denmark), $1 \%$ penicillin and streptavidin (Thermo Fisher Scientific, Inc.,
Waltham, MA, USA). Samples were immediately placed on ice and transported directly to the laboratory where they were processed (see below) within $1 \mathrm{~h}$ of collection. Information associated with the included patients $(n=13)$ is shown in Table I. Tumor staging was evaluated according to the Union for International Cancer Control classification system. None of the patients received any form of neo-adjuvant anticancer therapy. Tumor resections were performed at Bispebjerg Hospital, Copenhagen, Denmark between November 2014 and October 2015.

Cleavage of tumor tissue in vitro. A pool of tumor tissue from 2 patients was dissolved in PBS by mechanical blending and diluted 1:20 in protease specific buffer [MMP buffer $(50 \mathrm{mM}$ Tris- $\mathrm{HCl}, 200 \mathrm{mM} \mathrm{NaCl}, 10 \mathrm{mM} \mathrm{CaCl}_{2}, 100 \mu \mathrm{M} \mathrm{ZnSO}_{4}$ and $0.05 \%$ Brij 35 (Merck KGaA, Darmstadt, Germany), pH 7.5) or trypsin buffer $(50 \mathrm{mM}$ Tris- $\mathrm{HCl}, 150 \mathrm{mM} \mathrm{NaCl}, 5 \mathrm{mM}$ $\mathrm{CaCl}_{2}$ and $0.05 \%$ Brij 35, $\mathrm{pH}$ 7.5]. For each specific cleavage, $\sim 35 \mathrm{mg}$ tissue was used. MMP-2 and MMP-9 (BioCol GmbH, Michendorf, Germany) were activated with freshly prepared $1 \mathrm{mM}$ 4-aminophenylmercuric acetate (Sigma-Aldrich; Merck KGaA) in dimethyl sulfoxide by incubation at $37^{\circ} \mathrm{C}$ for $2 \mathrm{~h}$. Activated MMPs and trypsin (Sigma-Aldrich; Merck $\mathrm{KGaA}$ ) were added to the Eppendorf tubes containing tissue to a final concentration of $25 \mathrm{nM}$ and incubated overnight at $37^{\circ} \mathrm{C}$. Tissue dissolved in buffers only was used as a negative control. The reaction was terminated by adding EDTA to the MMP cleavage products or by adding aprotinin (BioCol $\mathrm{GmbH}$ ) to the trypsin cleavage products to a final concentration of $1 \mu \mathrm{M}$. The tissue samples were centrifuged at $10,000 \mathrm{x} \mathrm{g}$ at $4^{\circ} \mathrm{C}$ for $15 \mathrm{~min}$ and the supernatant was collected. The supernatant was stored at $-80^{\circ} \mathrm{C}$ until analysis by relevant ELISA.

Viability. The tumor tissue was cut into pieces of $\sim 2 \mathrm{~mm}^{3}$ and cultured in 96-well plates with $200 \mu \mathrm{l} /$ well DMEM:F12, $1 \%$ penicillin and streptavidin (Thermo Fisher Scientific, Inc.) at $37^{\circ} \mathrm{C}$ and $5 \% \mathrm{CO}_{2}$. Cell viability was tested in three different culture conditions: Upon addition of $2 \%$ fetal calf serum (FCS) (Sigma-Aldrich; Merck KGaA), upon addition of $2 \%$ Ultroser $^{\circledR} \mathrm{G}$ (Pall Life Sciences, Port Washington, NY, USA) and without the addition of FCS or Ultroser ${ }^{\circledR}$ G. To assess the metabolic activity of the tissue/cells, the medium was removed after $30 \mathrm{~min}$ and $24 \mathrm{~h}$, and alamarBlue ${ }^{\circledR}$ (Thermo Fisher Scientific, Inc.) was added to the cultures in a $10 \%$ dilution in PBS. alamarBlue ${ }^{\circledR}$ exhibits colorimetric changes as a function of the metabolic activity depending on proliferation and viability of the cells, and has previously been validated in the ex vivo culture setting (18). After $3 \mathrm{~h}$ of incubation with alamarBlue ${ }^{\circledR}$, the supernatants were collected and the absorbance determined at 540-590 $\mathrm{nm}$. The experiment was performed in quadruplicate for each condition and repeated twice (2 patients).

Ex vivo culture. The tissue was cut into pieces of $\sim 2 \mathrm{~mm}^{3}$ and cultured in the highest possible number of replicates (2-6 replicas per patient per tissue type) in a 96-well plate with $200 \mu \mathrm{l} /$ well DMEM:F12, $1 \%$ penicillin and streptavidin at $37^{\circ} \mathrm{C}$ and $5 \% \mathrm{CO}_{2}$. The supernatant was removed after $24 \mathrm{~h}$. Any cell/tissue debris was removed by centrifugation at 
Table I. Characteristics of patients.

\begin{tabular}{lc}
\hline Characteristic & Number of patients \\
\hline Age, mean \pm SD (range), years & $67.7 \pm 11.1(41-84)$ \\
Gender, female/male & $8 / 5$ \\
BMI, mean \pm SD (range), $\mathrm{kg} / \mathrm{m}^{2}$ & $28.5 \pm 5.4(21.6-36.0)$ \\
Tumor localization, colon/rectum & $10 / 3$ \\
Tumor stage, colon/rectum & \\
I & $3 / 0$ \\
II & $2 / 1$ \\
III & $4 / 1$ \\
IV & $1 / 1$ \\
\hline
\end{tabular}

BMI, body mass index; SD, standard deviation.

$10,000 \times \mathrm{g}$ for $15 \mathrm{~min}$ at $4^{\circ} \mathrm{C}$, and the supernatant was pooled and stored at $-80^{\circ} \mathrm{C}$ until analysis by the relevant ELISA.

Biomarker measurements. The levels of C3M (6) and VICM (9) were assessed in the culture supernatant by competitive ELISA. As is common for C3M and VICM assay procedures $(6,9)$, a biotinylated target peptide (Chinese Peptide Company, Beijing, China) was added to a 96-well streptavidin-coated plate in $40 \mathrm{mM} \mathrm{NaHPO} \cdot 12 \mathrm{H}_{2} \mathrm{O}, 7 \mathrm{mM} \mathrm{KHPO}, 137 \mathrm{mM}$ $\mathrm{NaCl}, 2.7$ mM KCl, 25 mM EDTA, 0.1\% Tween 20, 1\% BSA (Sigma-Aldrich; Merck KGaA) and 10\% sorbitol ( $\mathrm{pH} 7$ ) for C3M, or $50 \mathrm{mM}$ Tris- $\mathrm{HCl}, 1 \% \mathrm{BSA}, 0.1 \%$ Tween-20 and $0.36 \%$ 5-bromo-5-nitro-1,3-dioxane $\left(\mathrm{pH} 7.4\right.$ at $\left.20^{\circ} \mathrm{C}\right)$ for VICM. A total of $100 \mu \mathrm{l} /$ well was added and plates were then incubated for $30 \mathrm{~min}$ at $20^{\circ} \mathrm{C}$ while agitating at $300 \mathrm{rpm}$. The plate was washed five times in $20 \mathrm{mM}$ Tris- $\mathrm{HCl}$ and $50 \mathrm{mM} \mathrm{NaCl}$ buffer (washing buffer, $\mathrm{pH}$ 7.2). Next, $20 \mu \mathrm{l}$ target peptide calibrator (Chinese Peptide Company) or sample and $100 \mu \mathrm{l}$ horseradish peroxidase-conjugated monoclonal antibody specific for the target peptide sequence of interest (provided as part of C3M and VICM assay kits; cat. nos. 1200 and 1800, respectively; Nordic Bioscience A/S, Herlev, Denmark) was added. The anti-C3M antibody was dissolved (final concentration, $23 \mathrm{ng} / \mathrm{ml}$ ) in $8 \mathrm{mM}$ $\mathrm{NaHPO}_{4} \cdot 12 \mathrm{H}_{2} \mathrm{O}, 1.5 \mathrm{mM} \mathrm{KHPO}{ }_{4}, 13.7 \mathrm{mM} \mathrm{NaCl}, 2.7 \mathrm{mM}$ $\mathrm{KCl}, 0.1 \%$ Tween-20, $1 \%$ BSA and $0.003 \%$ phenol red (pH 7.4), and the anti-VICM antibody was dissolved (final concentration, $4 \mathrm{ng} / \mathrm{ml}$ ) in $50 \mathrm{mM}$ Tris- $\mathrm{HCl}, 1 \% \mathrm{BSA}, 0.1 \%$ Tween 20 and 0.36\% 5-bromo-5-nitro-1,3-dioxane ( $\mathrm{pH} 7.4$ at $20^{\circ} \mathrm{C}$ ). The $\mathrm{C} 3 \mathrm{M}$ and VICM assay kits were used according to the manufacturer's protocol. The plate was incubated for $1 \mathrm{~h}$ at $20^{\circ} \mathrm{C}(\mathrm{C} 3 \mathrm{M})$ or overnight at $4^{\circ} \mathrm{C}$ (VICM). The plate was washed five times in the aforementioned washing buffer prior to the addition of $100 \mu 1$ 3,3',5,5'-tetramethylbenzidine (Kem-En-Tec Diagnostics A/S, Taastrup, Denmark; cat. no. $438 \mathrm{OH})$. The plate was incubated for $15 \mathrm{~min}$ at $20^{\circ} \mathrm{C}$ in the dark. The reaction was stopped by the addition of $100 \mu \mathrm{l}$ stopping solution $\left(1 \% \mathrm{H}_{2} \mathrm{SO}_{4}\right)$ and the optical density was measured at $450 \mathrm{~nm}$ with $650 \mathrm{~nm}$ as a reference. Biomarker levels were determined in duplicate.

Statistical analysis. Statistical analysis was conducted using GraphPad Prism v6.05 (GraphPad Software, Inc., La Jolla,
CA, USA). Viability was compared using two-way analysis of variance adjusted for multiple comparisons with the Sidak test. Biomarker levels in the supernatant were compared using the Friedman test or the Kruskal-Wallis test adjusted for multiple comparisons with the Dunn's test. $\mathrm{P}<0.05$ was considered to indicate a statistically significant difference. The correlation between colorectal tumor tissue and corresponding NAT was calculated by the Pearson's correlation coefficient and goodness of fit. Results are presented as mean \pm standard error of the mean, Tukey plots or scatter plots.

\section{Results}

In vitro cleavage of colorectal tumor tissue. Following resection and mechanical processing, the tumor tissue was incubated with MMP-2, MMP-9 and trypsin to investigate if $\mathrm{C} 3 \mathrm{M}$ may be generated from the tissue in vitro. As illustrated in Fig. 1, the level of C3M increased by 20- and 10-fold upon incubating the tumor tissue with MMP-2 and MMP-9, respectively. By contrast, trypsin did not generate $\mathrm{C} 3 \mathrm{M}$. These findings suggest that $\mathrm{C} 3 \mathrm{M}$ is associated with colorectal tumor tissue and that $\mathrm{C} 3 \mathrm{M}$ is generated specifically by MMP cleavage.

Viability of ex vivo colorectal tumor tissue cultures under different culture conditions. The metabolic activity, as a measurement of viability, was assessed by addition of alamarBlue ${ }^{\circledR}$ for $3 \mathrm{~h}$ to the ex vivo cultures after $30 \mathrm{~min}$ and $24 \mathrm{~h}$ of primary culture. A total of three different culture conditions were investigated: Growth medium with $2 \%$ FCS, growth medium with $2 \%$ Ultroser $^{\circledR} \mathrm{G}$ and growth without FCS or Ultroser ${ }^{\circledR}$ G. The results are shown in Fig. 2. No significant difference was detected in the viability after $30 \mathrm{~min}$ or $24 \mathrm{~h}$, indicating that the ex vivo cultures stay viable for $\leq 24 \mathrm{~h}$ of culture. In addition, no difference was detected when comparing the three culture conditions, suggesting that the effect of either $2 \%$ FCS or $2 \%$ Ultroser $^{\circledR} \mathrm{G}$ on cell viability in the ex vivo cultures is of no importance for the conditions of the present study.

Biomarker release from ex vivo cultures of colorectal tumor tissue and NAT. Tumor tissue and corresponding NAT were removed during the resection of colorectal cancer in 13 patients. The tissue was cut into equally sized pieces and cultured for $24 \mathrm{~h}$ in growth medium without serum. As shown in Fig. 3A, only the tumor tissue generated significantly elevated levels of $\mathrm{C} 3 \mathrm{M}$ in the conditioned medium, with median levels of $3.7 \mathrm{ng} / \mathrm{ml}$ compared with those in the NAT and growth medium alone groups, which displayed median levels of C3M of 2.2 and $1.9 \mathrm{ng} / \mathrm{ml}$, respectively. As shown in Fig. 3B, VICM from the tumor tissue, median level of $0.51 \mathrm{ng} / \mathrm{ml}$, and the NAT, median level of $0.52 \mathrm{ng} / \mathrm{ml}$, was significantly increased compared with that from the growth medium alone, $0.03 \mathrm{ng} / \mathrm{ml}$. No significant differences were detected between the tumor tissue and NAT. Subsequently, the present study addressed the difference in biomarker levels according to tumor stage, and detected no significant difference (Fig. 4). Finally, no correlation was observed between biomarker levels released from the tumor tissue and corresponding NAT (Fig. 5). 


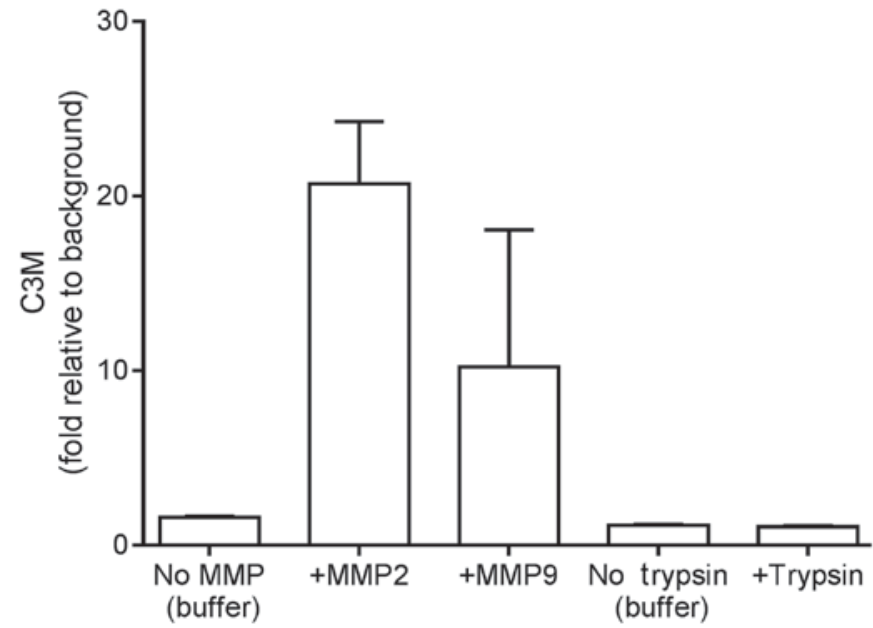

Tumor tissue

Figure 1. Degradation of type III collagen determined by level of C3M subsequent to the cleavage of colorectal tumor tissue with MMP-2, MMP-9 and trypsin. Data are plotted as the mean + standard error of the mean relative to the background levels, buffer alone without tissue. MMP, matrix metalloprotease; C3M, MMP-degraded type III collagen.

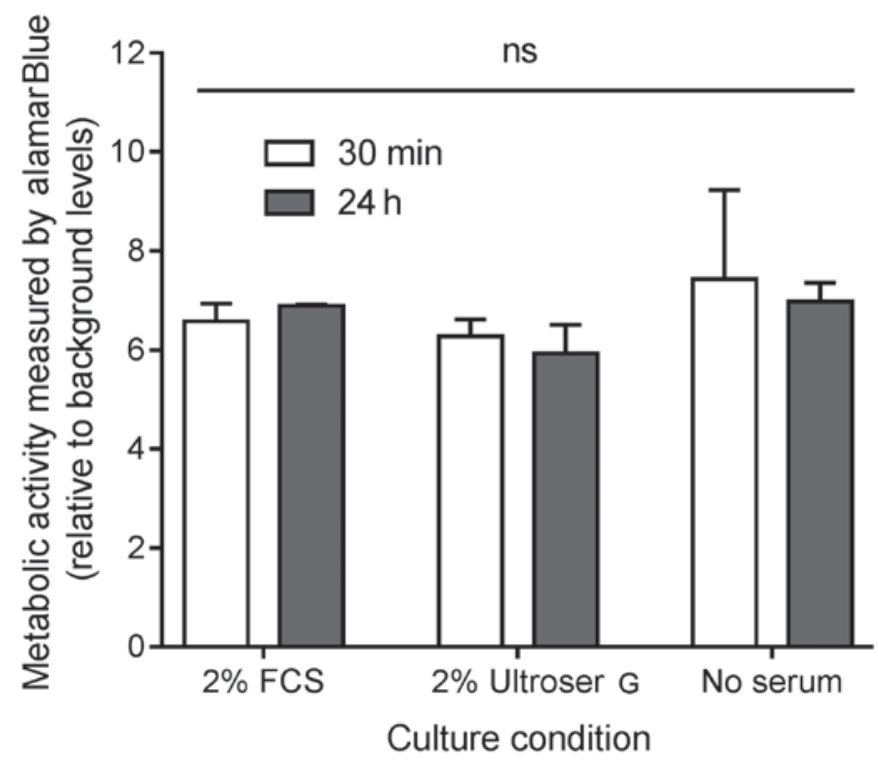

Figure 2. Metabolic activity and viability, of the colorectal tumor tissue culture after $30 \mathrm{~min}$ and $24 \mathrm{~h}$ of incubation with either growth medium alone, or with the addition of $2 \%$ FCS or $2 \%$ Ultroser $^{\circledR} \mathrm{G}$, a serum substitute. Data are plotted as the mean optical density + standard error of the mean relative to the background levels (optical density in medium alone) and compared using two-way analysis of variance. FCS, fetal calf serum; ns, not significant.

\section{Discussion}

The present study revealed that specific MMP-mediated molecular changes, particularly the degradation of $\mathrm{C} 3 \mathrm{M}$ and VICM, may be assessed in conditioned medium from ex vivo culture of biopsy tissue from patients with colorectal cancer. It is well established that such ex vivo culture of primary human tissues is a model that maintains tissue architecture and reflects ongoing dynamic changes in the tumor $(18,19)$, thereby retaining the majority of the complexity and heterogeneity of human tumors in a laboratory setting.
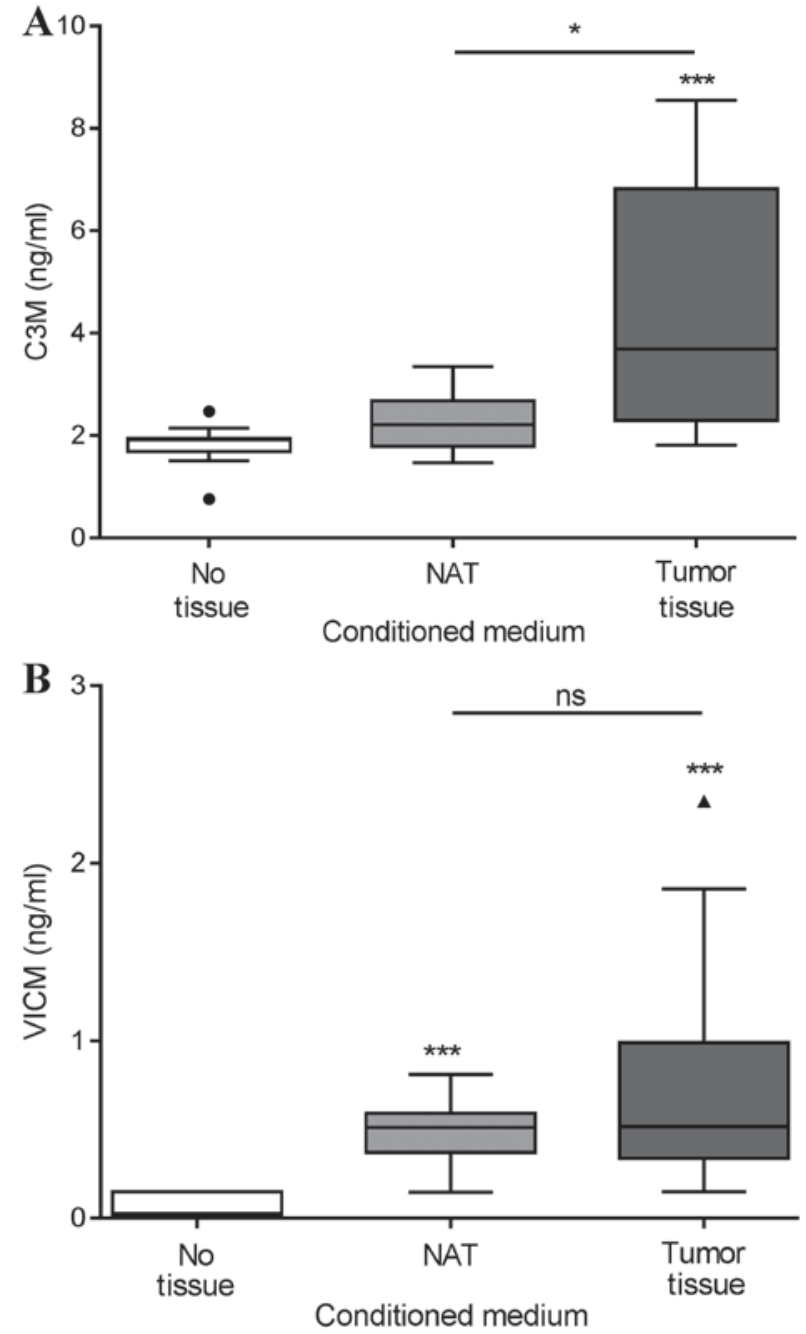

Figure 3. (A) C3M and (B) VICM in supernatant after $24 \mathrm{~h}$ of ex vivo culture of colorectal tumor tissue and corresponding NAT. Data are shown as Tukey plots, $n=13$. Levels were compared using the Friedman test with Dunn's multiple comparison test applied. ${ }^{*} \mathrm{P}<0.05,{ }^{* * *} \mathrm{P}<0.001$. MMP, matrix metalloprotease; C3M, MMP-degraded type III collagen; VICM, citrullinated and MMP-degraded vimentin; NAT, non-neoplastic adjacent tissue; ns, not significant.

Higher levels of C3M were released from tumor tissue compared with the corresponding levels of NAT; C3M levels of NAT did not differ from those detected in the growth medium alone. This suggests that $\mathrm{C} 3 \mathrm{M}$ is specifically associated with tissue remodeling of the tumor tissue, not NAT. The elevated levels of C3M in tumor tissue vs. NAT are hypothesized to be a result of the pathological turnover of the tissue. Therefore, the present findings indicate that $\mathrm{C} 3 \mathrm{M}$ may reflect disease activity at the time of resection. Whether the elevated $\mathrm{C} 3 \mathrm{M}$ levels are a result of specific ongoing inflammatory processes or altered cancer or stromal cell activities in the tumor remains to be established. However, C3M has been associated with inflammatory diseases of the gut (14), suggesting that C3M may reflect the extent of ongoing inflammation in the tumor tissue.

Tissue remodeling is a dynamic process that is ultimately the sum of protein formation, degradation and post-translational modifications (2). Normally, the ECM, including type III collagen, is maintained in a delicate equilibrium between protein formation and degradation. However, this balance may 

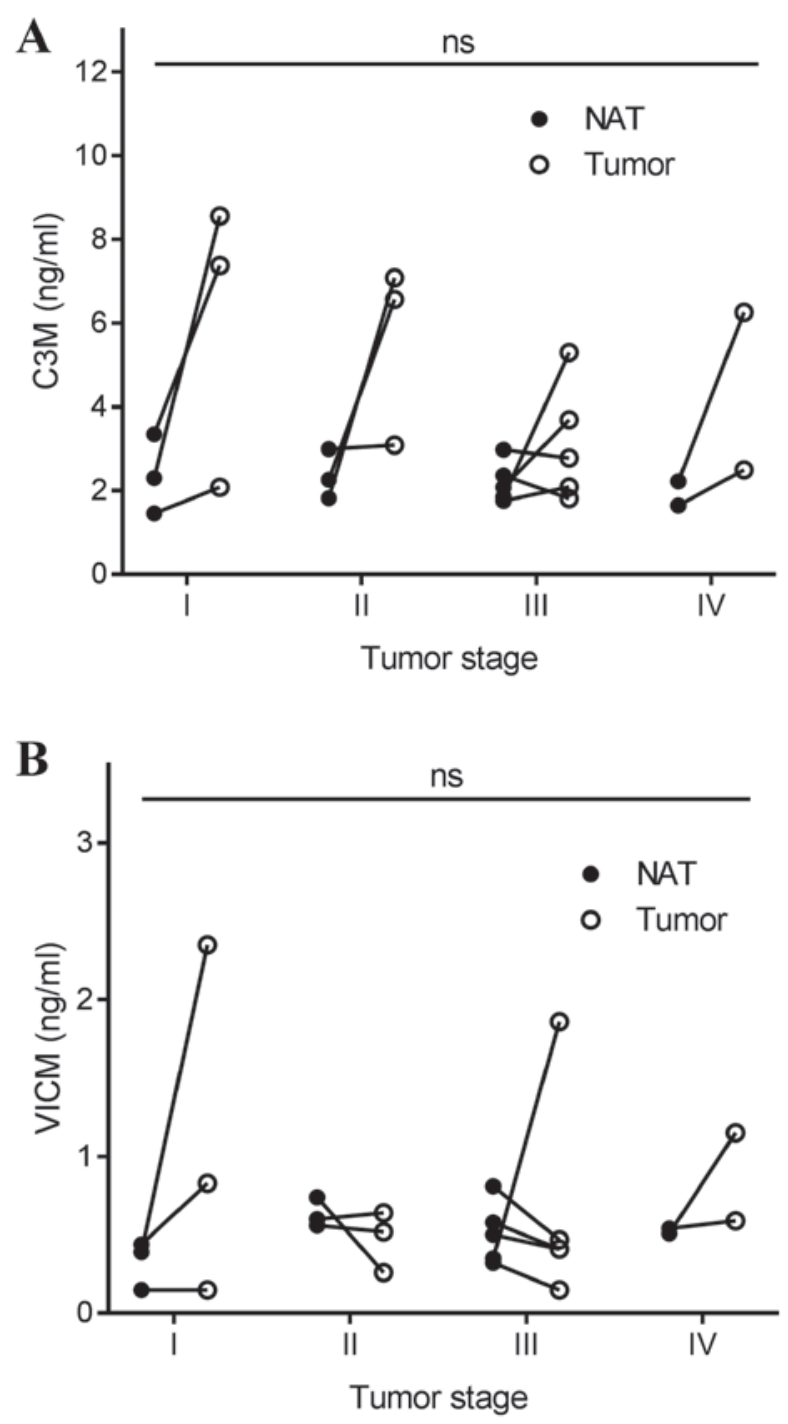

Figure 4. (A) C3M and (B) VICM in supernatant after $24 \mathrm{~h}$ of ex vivo culture of colorectal tumor tissue and corresponding NAT according to stage. The line illustrates paired NAT and tumor tissue. Levels were compared using the Kruskal-Wallis test adjusted for multiple comparisons. MMP, matrix metalloprotease; C3M, MMP-degraded type III collagen; VICM, citrullinated and MMP-degraded vimentin; NAT, non-neoplastic adjacent tissue; ns, not significant.

be altered in pathological conditions such as cancer, leading to the altered composition and quality of the ECM (8). The ECM and tissue remodeling are part of the malignant changes that drive cancer $(20,21)$. Thus, biomarkers reflecting dynamic changes such as ECM formation or degradation, and not merely the total protein content of ECM (22), are crucial for additional studies.

Proteolytic enzymes such as MMPs have been associated with the development and progression of colorectal cancer (23). It has also previously been shown that MMP-2 and MMP-9 protein expression is lower in NAT compared with that in the corresponding tumor tissue from patients with colorectal cancer (24). As C3M was generated by MMP-2 and MMP-9 (Fig. 1), this is in line with these previous studies. Notably, although the MMP-2 and MMP-9 levels were lower in NAT vs. tumor tissue in the study by Langers et al (24), the MMP
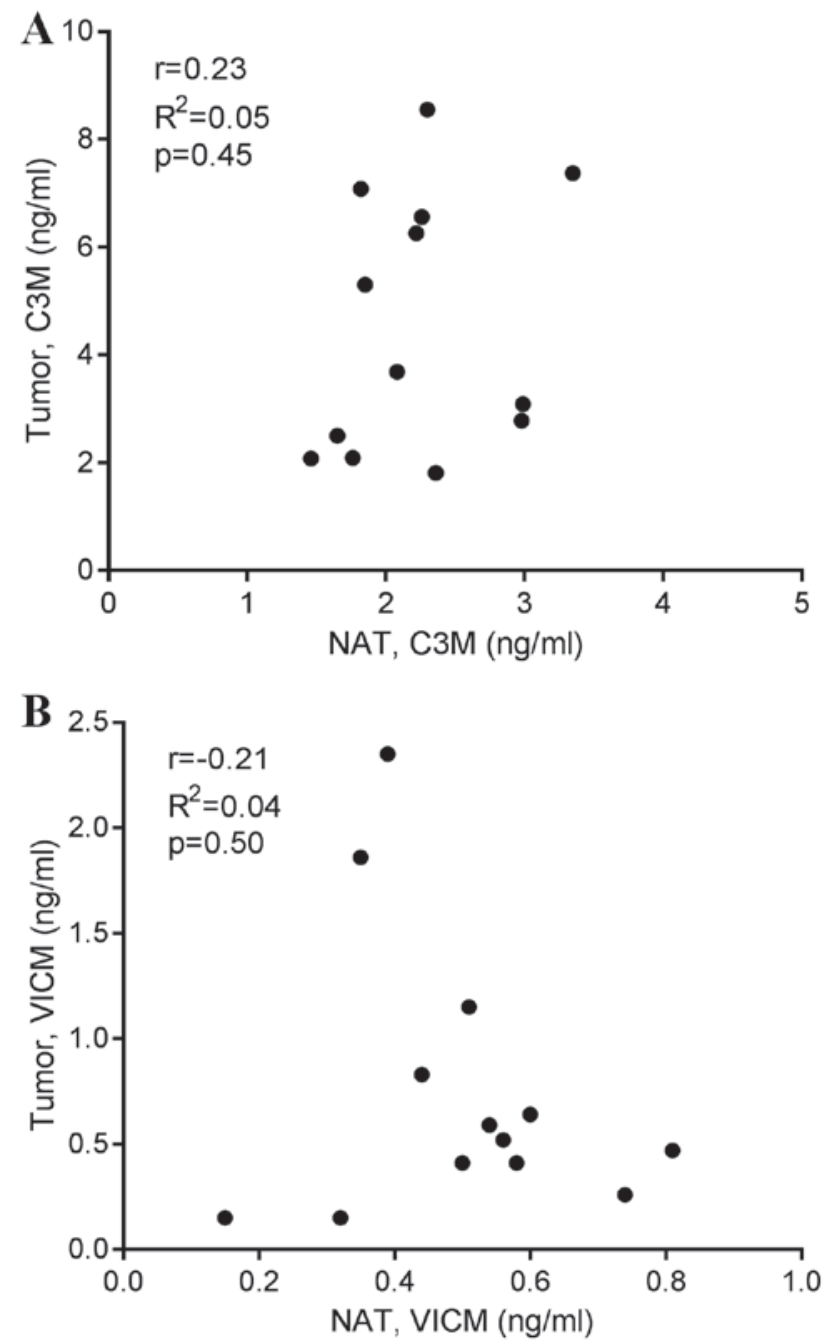

Figure 5. Correlation between colorectal tumor tissue and corresponding NAT for (A) C3M and (B) VICM in supernatant collected after $24 \mathrm{~h}$ of ex vivo culture. Indicated are the Pearson's correlation coefficient (r), the goodness of fit $\left(\mathrm{R}^{2}\right)$ and the P-value. MMP, matrix metalloprotease; C3M, MMP-degraded type III collagen; VICM, citrullinated and MMP-degraded vimentin; NAT, non-neoplastic adjacent tissue.

levels in NAT were still predictive of outcome (mortality), suggesting the biological relevance of assessing the molecular composition of NAT. Furthermore, the level of MMP-2, but not of MMP-9, was correlated between tumor tissue and NAT. The present study did not detect a correlation between biomarker levels in tumor tissue and corresponding NAT. Taken together, this indicates that investigating tumor and NAT biology in greater detail may yield essential information.

In contrast to $\mathrm{C} 3 \mathrm{M}$, the tumor tissue and NAT released VICM, and no difference was detected between the two types of tissue. VICM is a citrullinated protein, and citrullination of extracellular proteins is dependent on high levels of calcium (13). Enhanced calcium levels have been identified in tumor tissue and NAT from patients with colorectal cancer (25). It has been revealed that VICM is associated with activated macrophages (Willumsen et al, unpublished data). Therefore, the present findings may suggest ongoing macrophage activity in the tumor tissue and NAT from patients with colorectal cancer, and suggest that VICM may be applicable 
in an immuno-oncology setting by monitoring the activity of tumor-associated macrophages.

Although no correlation was observed between the stage of disease for C3M and VICM, the variation between individual patients in the levels released from the tumor tissue appeared to be more pronounced compared with the NAT findings. This may indicate that tumor tissues are more heterogeneous than NAT.

The relatively small number of patients involved limits the present study. Findings should be confirmed in larger clinical settings ultimately with progression or survival as primary endpoints. Investigating the effect of specific treatments may also be relevant, and potentially this model may serve as a promising preclinical tool for future drug-development studies. Additionally, the culture condition of colorectal cancer tissues may be a critical step that may affect the results. Although no effect was observed on viability as a function of culture media conditions, other factors may affect the outcomes, which require additional investigation. In addition, although the same volume of tissues were analyzed, a larger number of cells may be present in cancer tissue compared with that in the normal counterparts. Pathological analysis of cellularity and other tissue components such as total collagen content, should be performed in future studies to additionally interrogate the association between the tissue remodeling biomarkers and cancer.

Several other biomarkers exist for assessing ECM and microenvironmental alterations, and these may be relevant to include in future studies. In line with the present findings, biomarkers reflecting the MMP-mediated degradation of specific proteins of the tumor microenvironment have been observed to be significantly upregulated in serum from patients with various solid tumors compared with those in healthy controls. Elevated levels of different MMP-generated collagen degradation products have been observed in pancreatic (15), breast, ovarian (16), lung (17) and colorectal cancer (26).

In conclusion, by assessing MMP-mediated degradation of type III collagen and vimentin in an ex vivo model, the present study profiled and characterized colorectal tumor tissue and NAT, thus providing novel relevant insight into the dynamic changes occurring as part of the colorectal cancer pathogenesis. Detailed molecular characterization, including specific protein compositions and relevant post-translational modifications, as determined by evaluating the levels of citrullination and proteolysis of specific proteins, leads to an increased understanding of tumor-associated biology, and may provide novel biomarkers and targets for novel therapies. The increased understanding of the microenvironmental changes associated with colorectal cancer may ultimately help to improve the outcomes of individual patients.

\section{Acknowledgements}

The authors would like to acknowledge Miss Tina L. Brondum, Research Nurse, Digestive Disease Center, Bispebjerg Hospital, University of Copenhagen, DK-2400 Copenhagen, Denmark for her practical contribution to the present study and the Danish Research Foundation for funding the present study. N.W., C.L.B., A.-C.B.-J., S.N.K., D.J.L. and M.A.K. are employed at Nordic Bioscience A/S (Herlev, Denmark) and are involved in the development of biomarkers.

\section{References}

1. Balkwill FR, Capasso M and Hagemann T: The tumor microenvironment at a glance. J Cell Sci 125: 5591-5596, 2012.

2. Frantz C, Stewart KM and Weaver VM: The extracellular matrix at a glance. J Cell Sci 123: 4195-4200, 2010.

3. Mason SD and Joyce JA: Proteolytic networks in cancer. Trends Cell Biol 21: 228-237, 2011

4. Egeblad M and Werb Z: New functions for the matrix metalloproteinases in cancer progression. Nat Rev Cancer 2: 161-174, 2002.

5. Naba A, Clauser KR, Whittaker CA, Carr SA, Tanabe KK and Hynes RO: Extracellular matrix signatures of human primary metastatic colon cancers and their metastases to liver. BMC Cancer 14: 518, 2014.

6. Barascuk N, Veidal SS, Larsen L, Larsen DV, Larsen MR, Wang J, Zheng Q, Xing R, Cao Y, Rasmussen LM and Karsdal MA: A novel assay for extracellular matrix remodeling associated with liver fibrosis: An enzyme-linked immunosorbent assay (ELISA) for a MMP-9 proteolytically revealed neo-epitope of type III collagen. Clin Biochem 43: 899-904, 2010.

7. Hilska M, Collan Y, Peltonen J, Gullichsen R, Paajanen H and Laato M: The distribution of collagen types I, III, and IV in normal and malignant colorectal mucosa. Eur J Surg 164: 457-464, 1998

8. Karsdal MA, Nielsen MJ, Sand JM, Henriksen K, Genovese F, Bay-Jensen AC, Smith V, Adamkewicz JI, Christiansen C and Leeming DJ: Extracellular matrix remodeling: The common denominator in connective tissue diseases. Possibilities for evaluation and current understanding of the matrix as more than a passive architecture, but a key player in tissue failure. Assay Drug Dev Technol 11: 70-92, 2013.

9. Vassiliadis E, Oliveira CP, Alvares-da-Silva MR, Zhang C, Carrilho FJ, Stefano JT, Rabelo F, Pereira L, Kappel CR, Henriksen $\mathrm{K}$, et al: Circulating levels of citrullinated and MMP-degraded vimentin (VICM) in liver fibrosis related pathology. Am J Transl Res 4: 403-414, 2012.

10. Mor-Vaknin N, Punturieri A, Sitwala K and Markovitz DM: Vimentin is secreted by activated macrophages. Nat Cell Biol 5: 59-63, 2003.

11. Ngan CY, Yamamoto H, Seshimo I, Tsujino T, Man-i M, Ikeda JI, Konishi K, Takemasa I, Ikeda M, Sekimoto M, et al: Quantitative evaluation of vimentin expression in tumour stroma of colorectal cancer. Br J Cancer 96: 986-992, 2007.

12. Steinmetz NF, Cho CF, Ablack A, Lewis JD and Manchester M: Cowpea mosaic virus nanoparticles target surface vimentin on cancer cells. Nanomedicine (Lond) 6: 351-364, 2011.

13. Gudmann NS, Hansen NU, Jensen AC, Karsdal MA and Siebuhr AS: Biological relevance of citrullinations: Diagnostic, prognostic and therapeutic options. Autoimmunity 48: 73-79, 2015.

14. Mortensen JH, Godskesen LE, Jensen MD, Van Haaften WT, Klinge LG, Olinga P, Dijkstra G, Kjeldsen J, Karsdal MA, Bay-Jensen AC and Krag A: Fragments of citrullinated and MMP-degraded Vimentin and MMP-degraded type III collagen are novel serological biomarkers to differentiate crohn's disease from ulcerative colitis. J Crohns Colitis 9: 863-872, 2015.

15. Willumsen N, Bager CL, Leeming DJ, Smith V, Karsdal MA, Dornan D and Bay-Jensen AC: Extracellular matrix specific protein fingerprints measured in serum can seperate pancreatic cancer patients from healthy controls. BMC Cancer 13: 554, 2013.

16. Bager CL, Willumsen N, Leeming DJ, Smith V, Karsdal MA, Dornan D and Bay-Jensen AC: Collagen degradation products measured in serum can separate ovarian and breast cancer patients from healthy controls: A preliminary study. Cancer Biomark 15: 783-788, 2015.

17. Willumsen N, Bager CL, Leeming DJ, Smith V, Christiansen C, Karsdal MA, Dornan D and Bay-Jensen AC: Serum biomarkers reflecting specific tumor tissue remodeling processes are valuable diagnostic tools for lung cancer. Cancer Med 3: 1136-1145, 2014.

18. Pirnia F, Frese S, Gloor B, Hotz MA, Luethi A, Gugger M, Betticher DC and Borner MM: Ex vivo assessment of chemotherapy-induced apoptosis and associated molecular changes in patient tumor samples. Anticancer Res 26: 1765-1772, 2006.

19. Freeman AE and Hoffman RM: In vivo-like growth of human tumors in vitro. Proc Natl Acad Sci USA 83: 2694-2698, 1986. 
20. Bonnans C, Chou J and Werb Z: Remodelling the extracellular matrix in development and disease. Nat Rev Mol Cell Biol 15: 786-801, 2014

21. Pickup MW, Mouw JK and Weaver VM: The extracellular matrix modulates the hallmarks of cancer. EMBO Rep 15: 1243-1253, 2014.

22. Karsdal MA, Delvin E and Christiansen C: Protein fingerprints-relying on and understanding the information of serological protein measurements. Clin Biochem 44: 1278-1279, 2011.

23. Herszényi L, Barabás L, Hritz I, István G and Tulassay Z: Impact of proteolytic enzymes in colorectal cancer development and progression. World J Gastroenterol 20: 13246-13257, 2014.
24. Langers AM, Verspaget HW, Hawinkels LJ, Kubben FJ, van Duijn W, van der Reijden JJ, Hardwick JC, Hommes DW and Sier CF: MMP-2 and MMP-9 in normal mucosa are independently associated with outcome of colorectal cancer patients. $\mathrm{Br}$ J Cancer 106: 1495-1498, 2012.

25. Edelstein PS, Thompson SM and Davies RJ: Altered intracellular calcium regulation in human colorectal cancers and in 'normal' adjacent mucosa. Cancer Res 51: 4492-4494, 1991.

26. Kehlet SN, Sanz-Pamplona R, Brix S, Leeming DJ, Karsdal MA and Moreno V: Excessive collagen turnover products are released during colorectal cancer progression and elevated in serum from metastatic colorectal cancer patients. Sci Rep 6: 30599, 2016. 